\title{
Macronutrient intake and malabsorption in HIV infection: a comparison with other malabsorptive states
}

F Carbonnel, L Beaugerie, A Abou Rached, H D'Almagne, W Rozenbaum, Y Le Quintrec, J P Gendre, J Cosnes

\begin{abstract}
Background-Wasting is a major complication of HIV infection. The role of malabsorption in wasting is controversial. Aims-To assess oral intake and malabsorption in a cohort of weight losing HIV infected patients, with or without chronic diarrhoea.

Methods-A prospective study using a predefined protocol for HIV infected patients was performed in a gastroenterology and nutrition unit in a university hospital. A retrospective comparison was made with HIV negative patients with malabsorption due either to small bowel disease or resection. Body weight and height, serum albumin, oral intake of macronutrients, faecal weight, and faecal fat were measured.
\end{abstract}

Results-Seventy nine weight losing HIV infected patients were studied. Among the 66 patients with more than 5\% lipid malabsorption, wasting was significantly greater in patients with cryptosporidiosis $(n=22)$ than in patients with microsporidiosis $(n=18)$ who exhibited significantly more wasting than patients with no identified enteropathogen $(n=26)$ (body mass index 16.8 (14.0-20.7), 18.9 (16.5-21.3), 19.7 (15.9-23), respectively). When controlling for the level of lipid malabsorption, HIV infected patients had a significantly lower energy intake than HIV negative patients with chronic malabsorption. In HIV infected patients, but not in other categories of malabsorbers, body mass index correlated significantly with energy intake $(r=0.33,95 \%$ confidence intervals 0.12 to 0.51 ).

Conclusion-In weight losing HIV infected patients, reduced energy intake is superimposed on malabsorption and significantly contributes to wasting.

(Gut 1997; 41: 805-810)

Keywords: HIV; malabsorption; macronutrient intake

Chronic diarrhoea is an important complication of infection by the human immunodeficiency virus (HIV). It results in decreased quality of life, ${ }^{1}$ progressive wasting, ${ }^{23}$ and nutrient deficiencies. Recent studies have shown that reduced energy intake has a primary role in body weight loss of HIV infected patients. ${ }^{4}$ Malabsorption is also thought to contribute to malnutrition in such patients. ${ }^{2}$ Nutrient malabsorption has been assessed by the intestinal absorption of monosaccharides ${ }^{25-7}$ or ${ }^{14} \mathrm{C}$-glycerol tripalmitin. ${ }^{2}$ Keating et al found that in HIV infected adults, malabsorption of 3-O-methyl-Dglucose and D-xylose correlated with the body mass index (BMI). ${ }^{6}$ In HIV infected children, however, there appeared to be no correlation between D-xylose absorption and growth failure. $^{7}$ The effect of malabsorption on the nutritional state may depend not only on the severity and duration of malabsorption, but also on energy intake. Patients with chronic malabsorption due to extensive resection of the small bowel develop adaptive hyperphagia that tends to compensate for their absorptive handicap. ${ }^{8}$ Many of them are able to maintain an acceptable nutritional status in spite of notable malabsorption. To investigate the mechanisms of body weight loss in patients with chronic malabsorption, it is therefore necessary to measure their oral intake and faecal output simultaneously.

The aim of this study was to assess the relative contributions of malabsorption and reduced energy intake to body weight loss in HIV infected patients. For this purpose, we assessed oral intake and malabsorption in a cohort of HIV infected patients with body weight loss, with or without chronic diarrhoea. The results were compared with those obtained for patients who had chronic malabsorption due to small bowel resection or disease but were presumed to be HIV negative.

\section{Methods}

Body weight and height were measured and a three day prospective assessment of daily food intake with a simultaneous collection of faeces during the last 48 hours was performed in all consecutive patients with suspected malabsorption.

PATIENTS

HIV infected patients

Seventy nine HIV infected patients (five females and 74 males, median age 40 years, range 26-61) were studied between 1989 and 1994. They were referred from the infectious disease clinic for body weight loss and/or chronic diarrhoea. They were studied prospectively using a predefined, standardised protocol including stool examinations by light microscopy, culture, and a search for Clostridium 
TABLE 1 Comparison of different causes of malabsorption in HIV infected patients

\begin{tabular}{|c|c|c|c|c|c|c|}
\hline & \multirow[b]{2}{*}{$\begin{array}{l}\text { Cryptosporidiosis } \\
\text { (crypto) }(n=22)\end{array}$} & \multirow[b]{2}{*}{$\begin{array}{l}\text { Microsporidiosis } \\
\text { (micro) }(n=18)\end{array}$} & \multirow[b]{2}{*}{$\begin{array}{l}\text { No enteropathogen } \\
(n=26)\end{array}$} & \multicolumn{3}{|l|}{$p$ Value } \\
\hline & & & & $\begin{array}{l}\text { Cryptosporidiosis } v \\
\text { microsporidiosis }\end{array}$ & $\begin{array}{l}\text { Cryptosporidiosis v no } \\
\text { enteropathogen }\end{array}$ & $\begin{array}{l}\text { Microsporidiosis v no } \\
\text { enteropathogen }\end{array}$ \\
\hline Faecal weight $(\mathrm{g} / 24 \mathrm{~h})$ & $533(70-2810)$ & $440(165-2600)$ & $474(117-1050)$ & NS & NS & NS \\
\hline Energy intake $(\mathrm{MJ} / 24 \mathrm{~h})$ & $6.06(2.72-8.57)$ & $7.12(2.93-8.36)$ & $7.94(3.55-12.96)$ & NS & 0.01 & 0.2 \\
\hline BMI & $16.8(14.0-20.7)$ & $18.9(16.5-21.3)$ & $19.7(15.9-23)$ & $<0.05$ & $<0.001$ & $<0.05$ \\
\hline Serum albumin $(g / 1)$ & $37(21-46)$ & $35.5(26-42)$ & $38(29-48)$ & NS & NS & NS \\
\hline
\end{tabular}

difficile toxin. For those with diarrhoea, the workup also included gastroduodenoscopy and flexible rectosigmoidoscopy with multiple biopsies for light microscopy examination. As acute systemic infection is known to have an anorectic effect, patients with active cytomegalovirus enterocolitis or diarrhoea due to a curable bacterial enteropathogen (for example, $C$ difficile, Salmonella, Mycobacterium avium intracellulare, Shigella, or Campylobacter jejuni) were excluded from the analysis. The CD4 cell count (available in all but seven patients) was $16 / \mathrm{mm}^{3}$ (range 1-187). There were 65 homosexual/bisexual men, seven intravenous drug users, five cases of heterosexual contamination, one case of blood transmitted HIV infection, and one patient in whom the origin of HIV infection could not be determined. There were five patients with stage $B$ infection and 74 patients with stage $\mathrm{C}$ infection.

Controls

Two groups of patients, studied retrospectively, served as controls.

The first group comprised 85 postsurgical patients (41 females and 44 males, median age 47 years, range 15-83). Seventy five of them had short bowel syndrome (SBS). They were admitted between 1972 and 1994. Thirty one patients had a jejunoileal anatomosis and 44 had a jejunocolic anastomosis (loss of ileocolonic region); the remaining small bowel length was $65 \mathrm{~cm}$ (range 24-150). The last surgical procedure had been performed at least four months before evaluation. Patients were free of cancer and had not received nutritional support, radiotherapy, chemotherapy, or corticosteroids during the previous three months. Ten

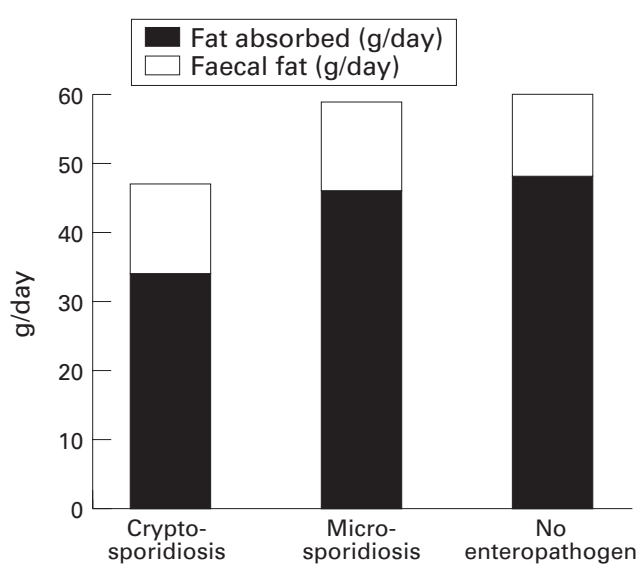

Figure 1: Median values for ingested and apparently absorbed lipids in patients with lipid malabsorption (more than 5\% of intake) associated with HIV infection, either due to cryptosporidiosis $(n=22)$, microsporidiosis $(n=18)$, or without detectable enteropathogen $(n=26)$. patients without malabsorption who had an ileo pouch anal anastomosis (IPAA) served as postsurgical controls.

The second group comprised 38 patients with small bowel disease (SBD) (20 females and 18 males, median age 45 years, range 16-72). None had undergone intestinal resection. There were 26 patients with coeliac disease, four with unexplained malabsorption, four with immune deficiency, one with Whipple's disease, one with chronic idiopathic pseudo-obstruction, one with giardiasis, and one with dermatomyositis. All patients with coeliac disease had total villous atrophy, demonstrated by small bowel biopsies performed shortly before study. Eighteen had newly diagnosed coeliac disease and were studied before the starting on a gluten free diet. Eight patients with refractory sprue were studied while on a gluten free diet.

ESTIMATED DIETARY RECORDS

All patients were asked to note their daily food intake for three days. This intake was estimated using household measures (spoons, cups, etc). On the fourth day, food intake was reviewed during an interview between the patient and a trained dietitian. This interview aimed to provide detailed data concerning oral intake. The amounts of energy, fat, carbohydrates, and proteins ingested were then calculated by the dietitian. Dietary records of HIV negative patients were performed during a hospital stay; HIV infected patients recorded their food intake while at home. Their interviews with the dietitians took place during a day hospital for HIV infected patients and during a hospital stay for HIV negative patients. Energy intake was expressed as ingested energy divided by ideal body weight according to sex and height. ${ }^{810}$

STOOL COLLECTIONS AND BIOCHEMICAL

ANALYSES

The 48 hour faecal collections were homogenised and weighed. The faecal fat level was determined by the method of Van deKamer et al. ${ }^{11}$ Lipid malabsorption was defined as the ratio of faecal fat to ingested fat. The patients were divided into three groups according to their lipid malabsorption level: group 1 included patients with $0-5 \%$ malabsorption (a non-significant level), group 2 included patients with malabsorption of 5-20\%, and group 3 , patients with more than $20 \%$ malabsorption. Faecal fat concentration was defined as the ratio of faecal fat to faecal weight. 

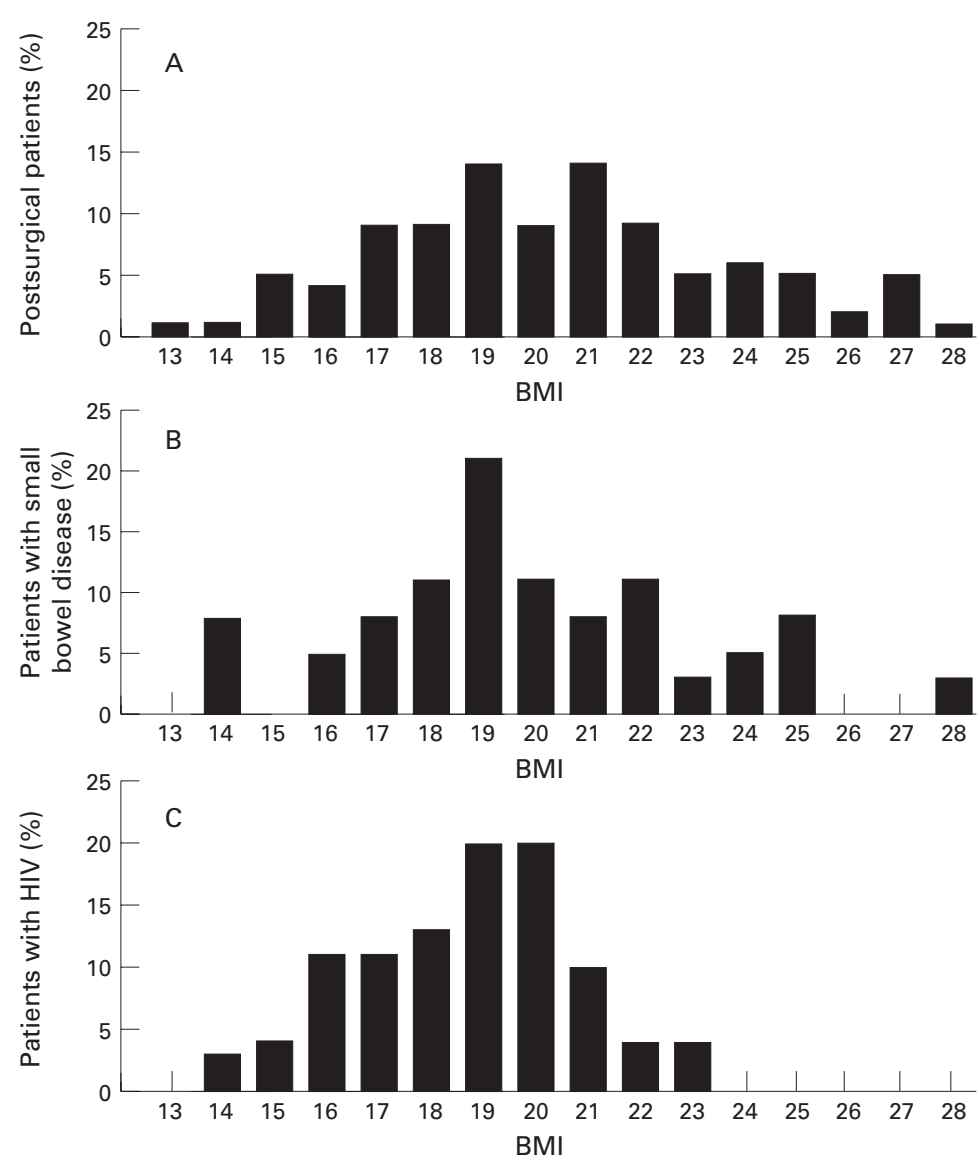

Figure 2: $\quad$ Distribution of BMI in postsurgical patients $(A)$, small bowel disease $(B)$, or HIV infection (C).

STATISTICAL ANALYSIS

Data are expressed as medians (range). A p value of 0.05 or less was considered statistically significant. Groups of patients were compared using the Kruskall-Wallis test (EPI-INFO software, EPI-INFO, Stone Mountain, Georgia, USA). When group comparisons were significant, pairs of populations were compared using non-parametric tests. ${ }^{12}$ Correlations between data were assessed using the Spearman coefficient.

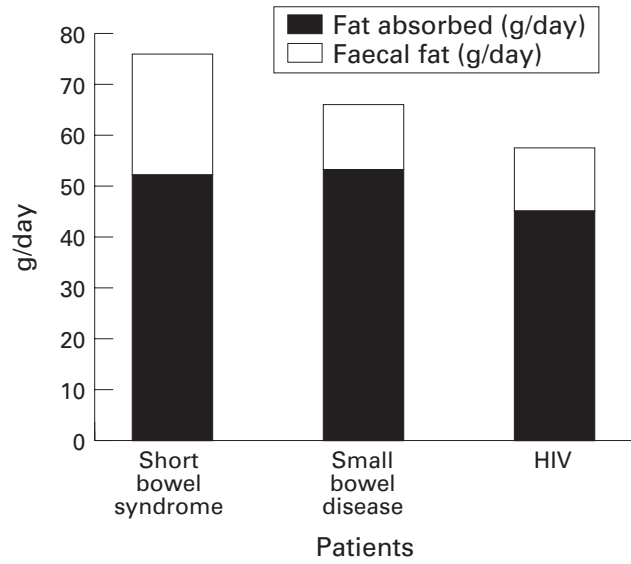

Figure 3: Median values for ingested and apparently absorbed lipids in patients with lipid malabsorption (>5\% of intake) associated with short bowel syndrome $(n=75)$, small bowel disease $(n=29)$, or HIV infection $(n=66)$.

\section{Results}

MALABSORPTION IN HIV INFECTED PATIENTS

Thirteen HIV infected patients without diarrhoea, referred for body weight loss (median actual weight $89(65-94) \%$ of usual body weight) were found to have a lipid malabsorption of less than $5 \%$. One of these patients had oral candidiasis, two had cryptosporidiosis, and two had lost weight during opportunistic systemic infections (Mycobacterium avium intracellulare infection in one and Pneumocystis carinii pneumonia in the other) and had been unable to regain it, long after effective control of the infection with specific antibiotic therapy. The remaining eight patients had unexplained body weight loss.

Sixty six patients had chronic diarrhoea and were found to have more than 5\% lipid malabsorption. They comprised 22 patients with cryptosporidiosis, 18 with microsporidiosis, and 26 without a detectable enteropathogen (four with stage B and 22 with stage C HIV infection). Remission was not obtained in these 66 patients with antidiarrhoeal drugs, paromomycin, metronidazole, or albendazole. Table 1 shows their body weight and oral intake according to the cause of malabsorption. Patients with cryptosporidiosis had a significantly lower BMI than those with either microsporidiosis or no enteropathogen. The cryptosporidiosis patients also had a lower energy intake than patients without an enteropathogen. Patients with microsporidiosis had a significantly lower BMI than patients with no enteropathogen.

Figure 1 shows the mean values for net lipid absorption in HIV infected patients with more than $5 \%$ lipid malabsorption. The level of net lipid absorption was significantly lower in patients with cryptosporidiosis than in patients without a detectable enteropathogen $(p=0.01)$. Lipid intake and steatorrhoea did not differ significantly between the three groups $(p=0.11$ and $\mathrm{p}=0.92$ respectively).

COMPARISON OF MALABSORPTION SYNDROMES

The HIV negative patients had a different sex ratio to the HIV group. There was no significant difference between the lipid absorption of men and women. Among the patients with postsurgical malabsorption or small bowel disease, men had a significantly higher energy intake than women $(\mathrm{p}=0.004$ and $\mathrm{p}=0.05$ respectively) when this intake was expressed in $\mathrm{kJ}$ per day. However, when energy intake was expressed as $\mathrm{kJ}$ per kg of ideal body weight per day, there was no significant difference between the intake of men and women. We therefore expressed energy intake as $\mathrm{kJ}$ per $\mathrm{kg}$ of ideal body weight. Lipid malabsorption and faecal weight were significantly correlated in postsurgical patients $(r=0.789, \mathrm{p}<0.0001)$, HIV infected patients $(r=0.799, \mathrm{p}<0.0001)$, and patients with SBD $(r=0.66, \mathrm{p}<0.0001)$. The faecal fat concentration (ratio of faecal fat to faecal weight) was significantly lower in HIV infected patients than in patients with SBD $(2.50 \%(0.24-11.17)$ versus $3.77 \%$ $(1.07-14.55), \quad \mathrm{p}=0.001) \quad$ or $\quad$ SBS $\quad(3.05 \%$ (0.37-13.33), $\mathrm{p}=0.05)$. In addition, faecal fat 
TABLE 2 Energy intake in patients with HIV infection, SBD, and postsurgical patients, either with IPAA or SBS

\begin{tabular}{|c|c|c|c|c|c|c|}
\hline & & & & \multicolumn{3}{|l|}{$p$ Value } \\
\hline & & & & $\begin{array}{l}\text { HIVv } \\
\text { surgical }\end{array}$ & $\begin{array}{l}H I V v \\
S B D\end{array}$ & $\begin{array}{l}S B D v \\
\text { surgical }\end{array}$ \\
\hline Lipid malabsorption $0-5 \%$ & $H I V(n=13)$ & $I P A A(n=10)$ & $S B D(n=9)$ & & & \\
\hline $\mathrm{BMI}$ & $19.6(14.7-22.6)$ & $22.5(16.8-27.0)$ & $17.0(12.7-26.5)$ & 0.01 & NS & 0.005 \\
\hline Energy intake (kJ/kg IBW/d) & $92(54-151)$ & $130(88-163)$ & $159(96-184)$ & 0.02 & $<0.001$ & $<0.2$ \\
\hline Lipid malabsorption $6-20 \%$ & $H I V(n=34)$ & $S B S(n=22)$ & $S B D(n=16)$ & & & \\
\hline $\mathrm{BMI}$ & $19.1(14.0-23.0)$ & $19.8(16.4-27.3)$ & $19.7(13.0-24.0)$ & 0.05 & $<0.10$ & NS \\
\hline Energy intake $(\mathrm{kJ} / \mathrm{kg}$ IBW/d) & $100(42-151)$ & $125(67-159)$ & $125(75-238)$ & $<0.001$ & $<0.002$ & NS \\
\hline Lipid malabsorption $>20 \%$ & $H I V(n=32)$ & $S B S(n=53)$ & $S B D(n=13)$ & & & \\
\hline BMI & $19.0(12.9-28)$ & $19.6(12.9-28)$ & $18.1(13.2-24.2)$ & $<0.10$ & NS & $<0.05$ \\
\hline Energy intake (kJ/kg IBW/d) & $92(38-167)$ & $134(67-301)$ & $113(59-155)$ & $<0.001$ & $<0.005$ & $<0.005$ \\
\hline
\end{tabular}

IBW, ideal body weight.

concentration was significantly higher in patients with SBD than patients with SBS $(\mathrm{p}=0.05)$.

As shown in fig 2, BMI of postsurgical patients (20.1 (12.9-28)) was significantly higher than that of patients with SBD (18.4 $(12.7-26.5), \mathrm{p}<0.001)$ and of HIV infected patients (19.1 (14-23), $\mathrm{p}<0.001)$.

As shown in fig 3, lipid intake was significantly higher in patients with SBS than HIV infected patients $(\mathrm{p}<0.001)$ or patients with SBD ( $\mathrm{p}<0.005)$, and significantly lower in HIV infected patients than patients with SBD $(p<0.005)$. Faecal fat was significantly higher in patients with SBS than HIV infected patients $(p<0.001)$ or patients with SBD $(p<0.001)$. Apparent lipid absorption was significantly lower in patients with HIV infection than in patients with SBS $(\mathrm{p}<0.01)$ or SBD $(\mathrm{p}=0.05)$.

Table 2 shows the results for energy intake and BMI in SBS, SBD, and HIV infected patients. At all three levels of lipid malabsorption, energy intake was significantly lower in HIV infected patients than in postsurgical patients or those with small bowel disease. In postsurgical patients, energy intake was significantly increased in patients with more than $20 \%$ lipid malabsorption compared with patients with 6-20\% lipid malabsorption $(\mathrm{p}<0.05)$. Among the patients with more than $20 \%$ lipid malabsorption, those who had undergone a jejunocolic anastomosis had a higher energy intake than those with a jejunoileal anatomosis (161 (67-301) kJ/kg/ $24 \mathrm{~h}$ versus $126(88-184) \mathrm{kJ} / \mathrm{kg} / 24 \mathrm{~h}, \mathrm{p}=0.04)$. Energy intake did not however differ significantly at any of the three levels of malabsorption, either in HIV infected patients or patients with SBD. BMI correlated significantly with lipid malabsorption in postsurgical patients ( $r=-0.290, \mathrm{p}=0.0036)$ but not in HIV infected patients or patients with SBD. In HIV infected patients, BMI correlated significantly with energy intake $(r=0.321, \mathrm{p}=0.0019)$. No correlation between energy intake and BMI was found in postsurgical patients or in those with SBD.

\section{Discussion}

We measured oral intake and malabsorption in a cohort of HIV infected patients with body weight loss, and compared them with other categories of patients with malabsorption. The results of this study suggest that malnutrition is greater in patients with cryptosporidiosis than in those with microsporidiosis and is greater in patients with microsporidiosis than in those with no identified enteropathogen. When controlling for the level of malabsorption, HIV infected patients had a lower energy intake than non-HIV infected patients with chronic malabsorption; hyperphagia consecutive to malabsorption appears to be confined to patients with postsurgical malabsorption. The pathophysiology of diarrhoea and malnutrition differed in HIV infected and non-HIV infected patients. Malabsorption correlated with faecal weight and thus had a prominent role in diarrhoea; however, in HIV infected patients, the faecal lipid concentration was significantly lower, suggesting higher intestinal secretion. Body weight loss seemed to result mainly from decreased energy intake in HIV infected patients, and from the extent of malabsorption in postsurgical patients.

Several methodological points should be discussed. Firstly, the non-HIV infected patients are of a different sex ratio to the HIV group. However, there were no differences between men and women as regards fat malabsorption and energy intake per kg of ideal body weight. Secondly, stools were collected over a period of 48 hours, and it has been recognised that stool collections over less than 72 hours generate significant intrasubject variations in faecal output. However, stool collection from outpatients with diarrhoea is difficult, particularly for those with frequent stools and/or large volume diarrhoea. Increasing the duration of stool collection up to 72 hours would have been impractical and could have increased the percentage of patients with an incomplete stool collection, especially of those with the most severe diarrhoea. The large number of patients involved and the fact that the resulting errors were unlikely to be systematically biased, means that the overall results are likely to be valid. However, the individual results of energy balance assessment should not be taken into account on the basis of a 48 hour stool collection. Thirdly, although the recording of dietary intake is certainly less accurate than the weighing of food, the same method was used for the three groups of patients, who were interviewed by the same dietitians and the cross comparison therefore seems valid. ${ }^{13}$ Moreover, HIV infected patients were ambulatory whereas the other patients were studied while staying in hospital. Since the hospital diet is less palat- 
able than that chosen by patients in their environment, it is likely that the reported differences between groups had been underestimated rather than overestimated. Fourthly, the optimum measure to assess weight loss needs to be discussed. The absolute reduction in weight is not appropriate, since the same reduction does not have the same consequences for subjects who are overweight, underweight, or who have a normal weight. ${ }^{14}$ The changes in percentage of premorbid body weight are subject to errors when premorbid body weight has been determined retrospectively. On the other hand, BMI is a valid marker of malnutrition. ${ }^{15}$

The present results agree with those reported earlier, which showed greater weight loss in patients with diarrhoea and occult enteric infections than in those with diarrhoea but no identified pathogen. ${ }^{16}$ Thus, Kotler et al found that D-xylose absorption and jejunal villus height were lower in HIV infected patients with chronic diarrhoea, malabsorption, and protozoan parasites than in patients without protozoan parasites. ${ }^{5}$ Similarly, Blanshard et al found that patients with chronic diarrhoea and an enteric pathogen had lower serum vitamin $\mathrm{B}_{12}$ than pathogen free patients, a result suggesting terminal ileal dysfunction. ${ }^{17}$ This dysfunction might contribute to diarrhoea and malabsorption. In the present study, the more severe body weight loss observed in patients with protozoan parasites can be attributed, at least in part, to reduced oral intake. The results of a recent study suggest that patients with such parasites have slower gastric emptying than parasite free patients. ${ }^{18}$ Since gastric emptying has been found to correlate with appetite, ${ }^{19}$ gastric emptying disturbances might explain the reduced energy intake observed in HIV infected patients with protozoan parasites. Furthermore, infection of the biliary tract with Cryptosporidium parvum or microsporidia often results in postprandial pain or discomfort which tends to reduce oral intake.

Malnutrition is a prominent feature of HIV infection and contributes to the morbidity and mortality of the disease. ${ }^{20}$ The pathophysiology of HIV related malnutrition is complex and multifactorial. Increases in resting energy expenditure have been described at all stages of HIV infection ${ }^{21}{ }^{22}$ but failed to correlate with body weight changes. Recently, Macallan et al showed that reduced energy intake had a primary role in the body weight loss of HIV infected patients. ${ }^{4}$ In their study, total energy expenditure was decreased, mainly because of reduced physical activity and energy intake correlated significantly with body weight changes. However, only a minority of their patients had chronic diarrhoea, and intestinal absorption was not assessed. The present study confirms and extends these results. Thus, we found that the HIV infected patients had lower levels of energy intake than the other categories of patients; this probably contributed to the lower body weight observed in HIV infected patients, since body weight and energy intake were correlated.
Patients with SBS and more than 20\% lipid malabsorption had an increased energy intake and their body weight was not significantly different from those with 5-20\% lipid malabsorption. Therefore, increased energy intake compensated for intestinal malabsorption and helped to maintain body weight. The mechanisms by which patients with a postsurgical short bowel compensate for their malabsorption are not clear. It has been postulated that the contact between malabsorbed nutrients in the intestinal lumen and the ileocolonic junction might inhibit appetite, because of the slowing of the gastric emptying rate due to the ileal brake. ${ }^{23}$ Indeed, among patients with a short bowel and more than $20 \%$ lipid malabsorption, a majority of patients had jejunocolic anastomosis and their energy intakes were found to be significantly higher than that of patients with jejunoileal anastomosis. Furthermore, it is possible that compensatory hyperphagia was due to the decrease in body weight observed at the highest level of malabsorption. Consequently, patients with a short bowel may have increased their oral intake in order to regain their usual weight. ${ }^{24}$ In the present study, the absence of hyperphagia in patients with HIV infection or SBD could be due to several factors. Firstly, these patients had had no resection of the ileocolonic junction. Secondly, their small intestine was inflamed, whereas the vast majority of patients with small bowel resection had no gross lesions of the remaining small bowel. Cytokines, particularly interleukin (IL) $1 \beta$ and tumour necrosis factor (TNF) $\alpha$, released by intestinal mucosa of HIV infected patients, ${ }^{25}$ and the IL- 6 and TNF- $\alpha$ released in coeliac patients, ${ }^{26}$ might inhibit food intake. Moreover, stimulated monocytes from HIV infected patients also produce IL-1 $\beta$ and TNF- $\alpha,{ }^{27}$ which have an anorectic effect. ${ }^{28}{ }^{29}$ Thirdly, in addition to small bowel involvement, HIV infected patients have delayed gastric emptying, ${ }^{18}$ and sometimes biliary involvement, which may also help to reduce oral intake.

Malnutrition is the most serious consequence of malabsorption. In AIDS patients with cryptosporidiosis, a prospective controlled trial has shown that paromomycin reduces oocyst excretion and the number of bowel movements, but no change in body weight was mentioned. ${ }^{30}$ An open study suggested that, in patients infected with Enterocytozoon bieneusi, albendazole reduces the number of bowel movements but does not significantly increase body weight. ${ }^{31}$ To our knowledge, no drug has been shown to correct malabsorption. As shown in this study, the effect of malabsorption is enhanced in HIV infected patients, by reduced oral intake. Every effort should therefore be made to maintain energy intake at an adequate level, taking malabsorption into account. Dietary counselling, oral supplements, and enteral nutrition should be attempted in mildly malnourished patients whose faecal output is not too high. For those patients with severe malnutrition and/or high faecal output, total parenteral nutrition does correct malnutrition, ${ }^{32}$ particularly in patients 
with malabsorption and no systemic infection. ${ }^{33}$

We are indebted to Monique Joubin, Michèle Nartz, and Patricia Gesbert who performed dietary records. We also thank the nursing staff of the Service de Gastroentérologie de l'Hôpital Rothschild for their excellent care of the patients.

1 Lubeck DP, Bennett CL, Mazonson PD, Fifer SK, Fries F. Quality of life and health service use among HIV-infected patients with chronic diarrhea. F Aquir Immune Defic Syndr 1993; 6: 478-84

2 Gillin JS, Shike M, Alcock N, Urmacher C, Krown S, Kurtz $\mathrm{RC}$, et al. Malabsorption and mucosal abnormalities of the small intestine in the acquired immunodeficiency syndrome. Ann Intern Med 1985; 102: 619-22.

3 Macallan DC, Noble C, Baldwin C, Foskett M, McManusT, Griffin GE. Prospective analysis of patterns of weight change in stage IV human immunodeficiency infection. Am f Clin Nutr 1993; 58: 417-24.

4 Macallan DC, Noble C, Baldwin C, Jebb SA, Prentice AM, Coward A, et al. Energy expenditure and wasting in human immunodeficiency virus infection. $N$ Engl F Med 1995; 333: 83-8.

5 Kotler DP, Francisco A, Clayton F, Scoles JV, Orenstein JM. Kotler DP, Francisco A, Clayton F, Scoles JV, Orenstein JM. Small intestinal injury and

6 Keating J, Bjarnarson I, Somasundaram S, Macpherson A, Francis N, Price AB, et al. Intestinal absorptive capacity, intestinal permeability and jejunal histology in HIV and their relation to diarrhea. Gut 1995; 37: 623-9.

7 Miller TL, Orav EJ, Martin SR, Cooper ER, McIntosh K, Winter HS. Malnutrition and carbohydrate malabsorption in children with vertically transmitted human immunodeficiency virus 1 infection. Gastroenterology 1991; 100: 1296 302 .

8 Cosnes J, Lamy P, Beaugerie L, Le Quintrec M, Gendre JP, Le Quintrec Y. Adaptive hyperphagia in patients with postsurgical malabsorption. Gastroenterology 1990; 99: 1814-9.

9 Messing B, Pigot F, Rongier M, Morin MC, Ndeïndoum U, Rambaud JC. Intestinal absorption of free oral hyperalimentation in the very short bowel syndrome. Gastroenterology 1991; 100: 1502-8.

10 Blackburn GL, Bistrian BR, Maini BS, Schlamm HT, Smith MF. Nutritional and metabolic assessment of the hospitalMF. Nutritional and metabolic assessment of the hospital-

ized patient. FPEN F Parenter Enteral Nutr 1977; 1: 11-22.
11 Van deKamer JH, Huinink, HTB, Weyers HA. Rapid method for determination of fat in the feces. 7 Biol Chem 1949; 177: 347-55.

12 Conover WJ. Some methods based on ranks. In: Conover WJ, ed. Practical nonparametric statistics. 2nd edn. New York: J Wiley and Sons, 1980; 229-37.

13 Dwyer JT. Dietary assessment. In: Shils ME, Olson JA Shike M, eds. Modern nutrition in health and disease. 8th edn. Philadelphia: Lea and Fibiger, 1994; 842-60.

14 Prentice AM, Goldberg GR, Jebb SA, Black AE, Murgatroyd PR, Diaz EO. Physiological response to slimming. Proc Nutr Soc 1991; 50: 441-58.

15 Ferro-Luzzi A, Sette S, Franklin M, James WPT. A simplified approach of assessing adult chronic energy deficiency. Eur f Clin Nutr 1992; 46: 173-86.

16 Greenson JK, Belitsos PC, Yardley JH, Bartlett JG. AIDS enteropathy: occult enteric infections and duodenal mu- cosa alterations in chronic diarrhea. Ann Int Med 1991; 114: 366-72.

17 Blanshard C, Francis N, Gazzard BG. Investigation of hronic diarrhea in acquired immunodeficiency syndrome. A prospective study of 155 patients. Gut 1996; 39: 824-33.

18 Neild PJ, Jewkes R, Gazzard BJ. Gastric emptying in human immunodeficiency virus seropositive patients: correlations with weight loss, autonomic function and gastrointestinal infection [abstract]. Gastroenterology 1996; 110: A724.

19 Carbonnel F, Lémann M, Rambaud JC, Mundler O, Jian R. Effect of energy density of a solid-liquid meal on gastric emptying and satiety. Am f Clin Nutr 1994; 60: 307-12.

20 Guenter P, Muurahainen N, Simons G, Kosok A, Cohan Guenter P, Muurahainen N, Simons G, Kosok A, Cohan
GR, Rudenstein R, et al. Relationships among nutritional $\mathrm{GR}$, Rudenstein R, et al. Relationships among nutritional
status, disease progression, and survival in HIV infection. $\mathcal{F}$ Aquir Immune Defic Syndr 1993; 6: 1130-8.

21 Melchior JC, Salmon D, Rigaud D, Leport C, Bouvet E, Detruchis $\mathrm{P}$, et al. Resting energy expenditure is increased in stable malnourished HIV-infected patients. Am $7 \mathrm{Clin}$ Nutr 1991; 53: 437-41.

22 Grunfeld C, Pang M, Shimizu L, Shigenaga JK, Jensen P, Feingold KR. Resting energy expenditure, caloric intake and short term weight change in human immunodeficiency syndrome. Am f Clin Nutr 1992; 55: 455-60.

23 Kotler DP, Tierney AR, Brenner SK, Couture S, Wang J, Pierson RN. Preservation of short-term energy balance in clinically stable patients with AIDS. Am f Clin Nutr 1990; clinically $7-13$

24 Leibel RL, Rosenbaum M, Hirsch J. Changes in energy expenditure resulting from altered body weight. $N$ Engl $\mathcal{F}$ Med 1995; 332: 621-8.

25 MacGowan I, Radford-Smith G, Jewell DP. Cytokine gene expression in HIV-infected intestinal mucosa. AIDS 1994; 8: $1569-75$.

26 Przemioslo RT, Kontakou M, Nobili V, Ciclitira PJ. Raised pro-inflammatory cytokines interleukin 6 and tumour necrosis factor $\alpha$ in celiac disease mucosa detected by immunohistochemistry. Gut 1994; 35: 1398-403.

27 Roux-Lombard P, Modoux C, Cruchaud A, Dayer JM. Purified blood monocytes from HIV1-infected patients produce high levels of TNF alpha and IL-1. Clin Immunol Imunopathol 1989; 50: 374-84.

28 Hellerstein MK, Meydani S, Meydani M, Wu K, Dinarello CA. Interleukin-1 induced anorexia in the rat. Influence of prostaglandins. F Clin Invest 1989; 84: 228-35.

29 Dinarello CA, Endres S, Meydani SN, Meydani M, Hellerstein MK. Interleukin-1, anorexia and dietary fatty acids. Ann NY Acad Sci 1990; 587: 332-8.

30 Clinton White A, Chappell CL, Sikander Hayat C, Kimball KT, Flanigan TP, Kimbal KT, et al. Paromomycin for cryptosporidiosis in AIDS: a prospective double blind trial. cryptosporidiosis in AIDS: a prosp

31 Dieterich DT, Lew EA, Kotler DP, Poles MA, Orenstein JM. Treatment with albendazole for intestinal disease due to Enterocytozoon bieneusi in patients with AIDS. F Infect Dis 1994; 169: 178-83.

32 Melchior JC, Chastang C, Gelas P, Carbonnel F, Zazzo JF, Boulier A, et al. Efficacy of 2-month parenteral nutrition in AIDS patients: a controlled randomized prospective trial. AIDS 1996; 10: 379-84.

33 Singer P, Rothkopf MM, Kvetan V, Kirvelä O, Gaare J, Askanazi J. Risks and benefits of home parenteral nutrition in acquired immunodeficiency syndrome. FPEN $\mathcal{F}$ Parenter Enteral Nutr 1991; 15: 75-9. 